\title{
Indicadores de Qualidade do Solo em Sistemas Agroecológicos no Cerrado Mineiro
}

\author{
Indicators of Soil Quality in Agroecological Systems in the Cerrado Mineiro
}

Ana Flávia Brandão Rocha

Ana Carolina Silva Siquieroli

Adriane de Andrade Silva

Amanda Mendes De Lima Carneiro

Bruno Nery Fernandes Vasconcelos

Danielle Davi Rodrigues Gondim

\begin{abstract}
Palavras-chave:
Agrofloresta

Respiração basal

Carbono da biomassa

microbiana

Atividade enzimática.

Resumo

A qualidade do solo é a sua capacidade de funcionar dentro dos limites do ecossistema e do uso da terra para assegurar a produtividade biológica, preservar a qualidade ambiental e promover a saúde dos vegetais e dos animais. Assim, o objetivo deste trabalho foi selecionar indicadores de qualidade de solo sensíveis às diferentes práticas agrícolas adotadas em áreas de sistemas agroecológicos na região do Cerrado Mineiro. As amostras de solos foram coletadas na camada de 0 a $20 \mathrm{~cm}$ da superfície, no final do período de seca, em três diferentes propriedades agrícolas familiares que se dedicam ao cultivo agroecológico (CA) localizadas nos municípios de Romaria e Uberlândia, Minas Gerais, Brasil. Foram avaliadas 10 amostras de solo, sendo cinco áreas com manejo agroecológico e cinco áreas de pasto, como referência. Foram avaliados os atributos químicos, população da microbiota, carbono da biomassa microbiana (CBM), respiração basal (RBS) e atividade das enzimas beta-glucosidase, fosfatase e arilsulfatase. As variáveis respiração basal, beta-glucosidase, $\mathrm{pH}$, colônias de bactérias e de actinobactérias foram sensíveis aos diferentes manejos de cultivo agroecológico (CA) e pasto, podendo assim ser utilizadas como indicadores de qualidade de solo. Os valores médios entre a razão de CA e pasto destes indicadores foram 1,69, 1,20, 3,57 e 2,44, respectivamente. As áreas de cultivo agroecológico apresentaram um solo de melhor qualidade e, possivelmente, maior atividade das suas funções básicas.
\end{abstract}

Keywords:

Agroforestry

Soil basal respiration

Microbial biomass carbon

Enzymatic activity

\footnotetext{
1 Universidade Federal de Uberlândia - UFU, Uberlândia, MG, Brasil. anaflaviabrand@gmail.com

2 Universidade Federal de Uberlândia - UFU, Monte Carmelo, MG, Brasil carol@ufu.br

${ }^{3}$ Universidade Federal de Uberlândia - UFU, Monte Carmelo, MG, Brasil adriane@ufu.br

${ }^{4}$ Universidade Federal de Uberlândia - UFU, Monte Carmelo, MG, Brasil amandamlc.ac@gmail.com

5 Universidade Federal de Uberlândia - UFU, Monte Carmelo, MG, Brasil brunonery@ufu.br

${ }^{6}$ Universidade Federal de Uberlândia - UFU, Monte Carmelo, MG, Brasil danielledrg@ufu.br
} 


\section{INTRODUÇÃO}

A agroecologia refere-se a princípios de práticas de produção agrícola que melhoram os sistemas ecológicos. Isso inclui a reciclagem de nutrientes, melhoria dos solos e aumento das interações entre os diferentes componentes. Como exemplo, pode ocorrer a integração de animais e safras, plantio de outras culturas, e também aumento da biodiversidade (WACH, 2021). Fornece os princípios para gerenciar agroecossistemas produtivos e garantir a conservação de recursos naturais (ALTIERI; KOOHAFKAN, 2008). Essa prática visa redesenhar o sistema alimentar, englobando as dimensões ecológica, econômica e social da sustentabilidade (CIACCIA et al., 2019; WOOD et al., 2015).

Modelos agrícolas alternativos e sustentáveis, como a agroecologia, tendem a reduzir os efeitos ambientais ou sociais adversos da agricultura convencional que afetam negativamente as áreas rurais (SKRZYPCZYŃSKI et al., 2021). O movimento agroecológico se desenvolveu em oposição ao uso de insumos agroquímicos como pesticidas e fertilizantes inorgânicos, mecanização e monoculturas, visto que essas práticas esgotam os solos, reduzem a biodiversidade, poluem os cursos d'água e causam outros danos ambientais (WACH, 2021). A adoção de sistemas agroecológicos tem sido impulsionada, principalmente, pela demanda da sociedade por alimentos mais saudáveis e para que a produção resulte em menores impactos ambientais negativos (FERREIRA et al., 2017; LIMA et al., 2020). Uma perspectiva agroecológica vincula o valor nutricional dos alimentos aos impactos ambientais da produção de alimentos. Essa reconexão entre ecologia e nutrição, que está na base da reconexão entre agricultura, meio ambiente e alimentos, levanta questões éticas e ontológicas fundamentais sobre nosso lugar como humanos no sistema mais amplo, em que, de acordo com a teoria ecológica, enfatiza a interconexão de diferentes espécies e coloca os humanos como apenas uma parte de um ecossistema (LAMINE; DAWSON, 2018).

De acordo com Bünemann et al. (2018), a qualidade do solo é mensurada pela capacidade do solo de funcionar dentro dos limites do ecossistema e do uso da terra para assegurar a produtividade biológica, preservar a qualidade ambiental e promover a saúde das plantas e animais. O conceito de qualidade do solo foi desenvolvido para poder avaliar a condição de um solo sob um manejo específico (SARMIENTO; et al 2018). A relevância da utilização de indicadores está ligada à expressão da funcionalidade do solo, o que evidencia as deficiências das áreas avaliadas e orienta para a recuperação do solo (CAVALCANTE et al., 2020).

Alguns exemplos de indicadores de qualidade do solo são o carbono da biomassa microbiana, a respiração basal e as atividades enzimáticas, os quais são importantes para avaliar os efeitos do cultivo e alterações do uso da terra. Em especial, a biomassa microbiana do solo e as enzimas geralmente respondem mais rapidamente à perturbação das práticas agrícolas ou às mudanças nas condições ambientais em relação a outras variáveis do solo (RAIESI; BEHESHTI, 2014). Além dos indicadores biológicos e físicos, os indicadores químicos também são utilizados para mensurar a qualidade do solo (ARAÚJO et al., 2012).

Esse trabalho destaca os indicadores de qualidade de solo mais adequados para serem utilizados em análises de qualidade do solo no bioma Cerrado no estado de Minas Gerais, visto que existe uma ampla quantidade de variáveis que podem ser utilizadas a esse fim, mas algumas delas não apresentam resultados significativos. Assim, o objetivo deste trabalho foi selecionar indicadores de qualidade de solo para sistemas agroecológicos da agricultura familiar no Cerrado Brasileiro, nos municípios de Uberlândia e Romaria.

\section{MATERIAL E MÉTODOS}

\section{Caracterização da área de estudo}

Nesse estudo foram analisadas três propriedades agroecológicas da agricultura familiar, sendo que as propriedades 1 e 2 desenvolvem sistemas agroecológicos dentro de um mesmo assentamento rural na cidade de Uberlândia-MG, os quais foram implantados em 2015 e a transição para a produção agroecológica foi finalizada em 2017. A outra propriedade rural agroecológica está localizada na cidade de Romaria-MG. As propriedades 1 e 3 participam de Organizações de Controle Social (OCS), sendo seus produtores certificados como orgânicos pelo Ministério da Agricultura, Pecuária e Abastecimento (MAPA). Os alimentos orgânicos e os alimentos agroecológicos não possuem agrotóxicos, um dos pontos que os diferenciam é que alimento agroecológico possui uma ideologia ampliada, que abrange relações com a natureza, comércio e relações de trabalho justos, revisão dos padrões de consumo e são baseados na agricultura familiar (WARMLING, 2014). Além 
disso, a certificação do alimento orgânico é realizada por "auditoria" e a do alimento agroecológico é uma certificação "participativa" (ABREU et al. 2012).

A propriedade agrícola familiar 1, localizada em Uberlândia-MG, de coordenadas geográficas $19^{\circ} 04^{\prime} 05.0^{\prime \prime S} 48^{\circ} 27^{\prime} 51.6^{\prime \prime} \mathrm{W}$ (Figura 1) tem uma área total de $12,5 \mathrm{ha}$, sendo $2.493 \mathrm{~m}^{2}$ ocupados por um sistema agroecológico e agroflorestal (CA1) e uma área ao lado destinada à produção agroecológica (CA2). As espécies agrícolas e florestais encontradas na área CA1 foram: mamão, manga, angico vermelho, embaúba, jatobá, ipê roxo, mutambo, tamboril, guariroba, eucalipto, mamona, feijão guandu, capim elefante, margaridão, gliricídia, feijão de porco, mucuna e capim brachiaria. Já na área CA2 foram encontrados: alho, capim limão, cebolinha, coentro, erva cidreira, hortelã, pimenta, salsa, cebola, acerola banana, limão, maracujá, goiaba, amora, caju, feijão macaço; milho; abobrinha, berinjela, jiló, tomate cereja, maxixe, morango, alface, alho poró, almeirão, beldroega, brócolis, couve espinafre, mostarda, repolho, rúcula, batata doce, beterraba, araruta, cenoura, rabanete, inhame, mandioca, batata yacon, e girassol (SILVA, 2019).

O principal aspecto que diferencia a área de CA1 e de CA2 dessa propriedade é que no CA2 há uma predominância de hortaliças e o CA1 é constituído em sua maior parte por espécies arbóreas. O produtor rural dessa propriedade, por questões ambientais, deixou uma área para recomposição agroflorestal (área de CA1), com exploração dos cultivos que já haviam sido implantados antes de 2015, mas sem a reintrodução de hortaliças, as quais dependeriam de adubação constantemente. Além disso, o CA2 possui uma maior diversidade e quantidade de espécies vegetais. As áreas de CA1 e CA2 dessa propriedade são irrigadas com efluente aquícola das tilápias, que é rico em nutrientes (SILVA, 2019). Além disso, essas duas áreas recebem aportes de Yoorin, que também contém fósforo, cálcio, magnésio, silício e outros nutrientes, e fosfato bicálcico. A adição desses insumos agrícolas é permitida pelas normativas de cultivos agroecológicos/orgânicos. Também foram incorporados compostos orgânicos no solo dessas áreas, que são fontes de macro e micronutrientes.

Figura 1 - Localização das propriedades agrícolas familiares. Propriedades 1 e 2: manejadas com cultivo agroecológico localizadas no Município de Uberlândia, MG; Propriedade 3: cultivo agroecológico, localizado no Município de Romaria, MG.

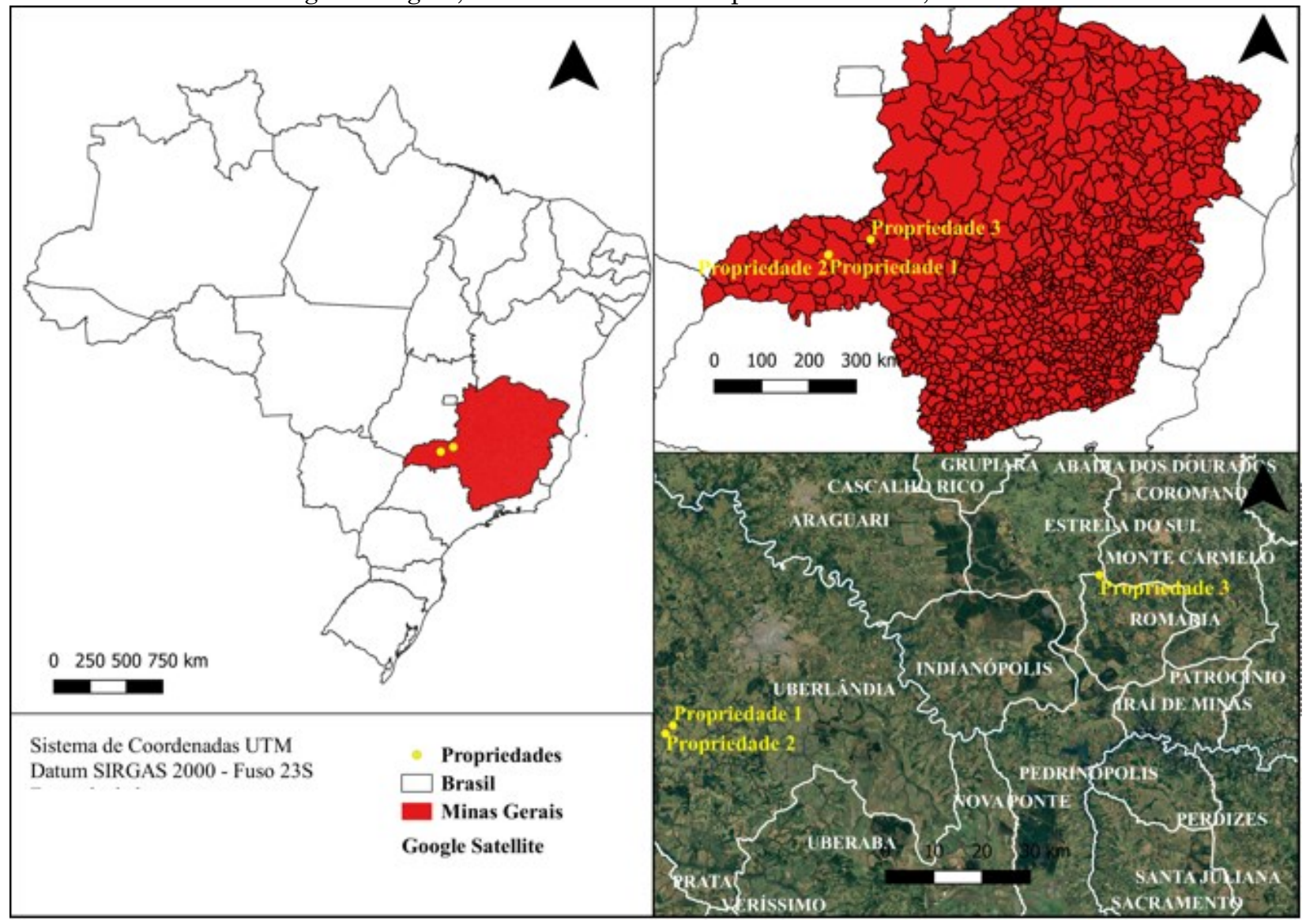

Fonte: Os autores (2021). 
$\mathrm{Na}$ propriedade 1 foram coletadas duas amostras por se tratar de áreas com práticas agrícolas distintas: CA1 corresponde ao manejo agroecológico e agroflorestal implantado em 2015; e CA2 que corresponde ao manejo agroecológico com a predominância de hortaliças, implantado em 2017, além das duas amostras de pasto utilizadas como referência.

A tabela 1 apresenta as características dos solos coletados nas 3 propriedades rurais para as 10 amostras diferentes. A classificação do solo foi realizada de acordo com a metodologia descrita por Teixeira (2017).

Tabela 1 - Classificação taxonômica dos solos nos locais de amostragem.

\begin{tabular}{cccc}
\hline Propriedade & Amostra & Solo $^{1}$ & Município \\
\hline & CA1 & $\begin{array}{c}\text { Neossolo Quartzarênico } \\
\text { hidromórfico }\end{array}$ & \\
\cline { 2 - 3 } 1 & CA 2 & $\begin{array}{c}\text { Latossolo Vermelho Distrófico, } \\
\text { textura média, extrato inferior da } \\
\text { paisagem }\end{array}$ & Uberlândia \\
\hline & CA 3 & $\begin{array}{c}\text { Latossolo Vermelho Distrófico, } \\
\text { textura média, extrato superior } \\
\text { da paisagem }\end{array}$ & Uberlândia \\
\hline 3 & CA 4 & $\begin{array}{c}\text { Latossolo Vermelho Distrófico - } \\
\text { textura argilosa, extrato inferior } \\
\text { da paisagem }\end{array}$ & Romaria \\
\hline
\end{tabular}

Fonte: Os autores (2021).

Antes da intervenção agroecológica, a principal atividade que era exercida no lote das propriedades 1 e 2 , pelo antigo proprietário da fazenda, era a criação de gado de corte, e assim, a maior parte da paisagem do sítio é caracterizada atualmente por pastagem degradada. Atualmente, há criação de alguns suínos em chiqueiro, vaca, boi e de galinhas na área de pasto nas propriedades do Assentamento Celso Lúcio. As áreas de Pasto 1 e Pasto 2 correspondem a essas áreas de pastagem que não sofrem interferência por um tempo.

A propriedade agrícola familiar 2, com coordenadas $\quad 19^{\circ} 04^{\prime} 59.5^{\prime \prime} \mathrm{S} \quad 48^{\circ} 28^{\prime} 46.0^{\prime \prime} \mathrm{W}$, localizada no município de Uberlândia, MG (Figura 1), possui área total de 13,2 ha, sendo destinados $1.018 \mathrm{~m}^{2}$ ao cultivo agroecológico e agroflorestal desde 2015. Nessa área são encontradas hortaliças e espécies arbóreas. As espécies vegetais encontradas nessa propriedade são: coentro, erva cidreira, gengibre, hortelã, manjericão, pimenta, salsa, arruda, açafrão, boldo, funcho, cebola, abacate, acerola, banana, limão, mamão, manga, goiaba, caju, laranja, mexerica, feijão macaço, milho, abobrinha, jiló, pimentão, quiabo, maxixe, morango, agrião, alface, almeirão, beldroega, chicória, couve, mostarda, rúcula, taioba, batata doce, araruta, inhame, mandioca, guariroba, faveiro-do-cerrado, eucalipto, mamona, feijão guandu, capim elefante, magaridão, gliricídia, feijão de porco, mucuna e capim brachiaria (SILVA, 2019). Além disso, o produtor agrícola dessa área realiza incorporação da matéria orgânica no solo dos canteiros.

Por fim, tem-se a propriedade agrícola familiar com coordenadas $18^{\circ} 48^{\prime} 3.02 " \mathrm{~S}$ $47^{\circ} 37^{\prime} 13.10^{\prime \prime}$ (Figura 1), localizada no município de Romaria, MG. Esse produtor realiza cultivo agroecológico nas duas áreas de sua propriedade (CA4 e CA5) mantendo as práticas agroecológicas de reciclagem de biomassa oriunda de podas de árvores, capineiras e restos de cultura, uso da cobertura morta formada por palhada e serapilheira de mata nativa (cerrado), rotação de culturas, adubação verde e outras práticas que promovem a reciclagem de nutrientes. Nessa propriedade em ambas as áreas são cultivadas plantas diversas em pleno sol como: mamão, capim limão, cebolinha, coentro, erva cidreira, hortelã, pimenta, salsa, cebola, acerola, banana, limão, berinjela, jiló, tomate, alface, alho poró, almeirão, brócolis, couve, espinafre, mostarda, repolho, rúcula, batata doce, beterraba, cenoura, mandioca e batata yacon (SILVA, 2019). 


\section{Amostragem}

As amostras de solos foram coletadas à uma profundidade de 20 a $25 \mathrm{~cm}$, com o auxílio de um enxadão. As coletas das amostras foram realizadas de forma aleatória dentro dos sistemas de cultivo dos agricultores. Em adição, as amostras foram compostas por cinco pontos por área, sendo removida a serrapilheira e evitando locais próximos às árvores.

As coletas foram realizadas entre os meses de setembro e outubro de 2019 (final do período de seca), em pontos georreferenciados. Também foram coletadas amostras de solo de áreas destinadas à pastagem muito próximas aos pontos de coleta para servirem como referência de ausência de um manejo agroecológico, representando áreas vizinhas, em mesmo clima e em solos semelhantes, com outro sistema de cultivo e que não receberam intervenção pelos agricultores. As amostras de pasto desse trabalho constituem um tratamento comparativo ao sistema agroecológico e agroflorestal.

A Figura 2 apresenta a precipitação acumulada dos seis meses anteriores ao dia de coleta das amostras de solo nos municípios de Uberlândia e Romaria e a Figura 3 apresenta a temperatura no mês em que foram coletadas as amostras nessas cidades.

Figura 2 - Chuva diária acumulada $(\mathrm{mm})$ nos seis meses anteriores à coleta das amostras de solos nos municípios de Uberlândia e Romaria, MG.

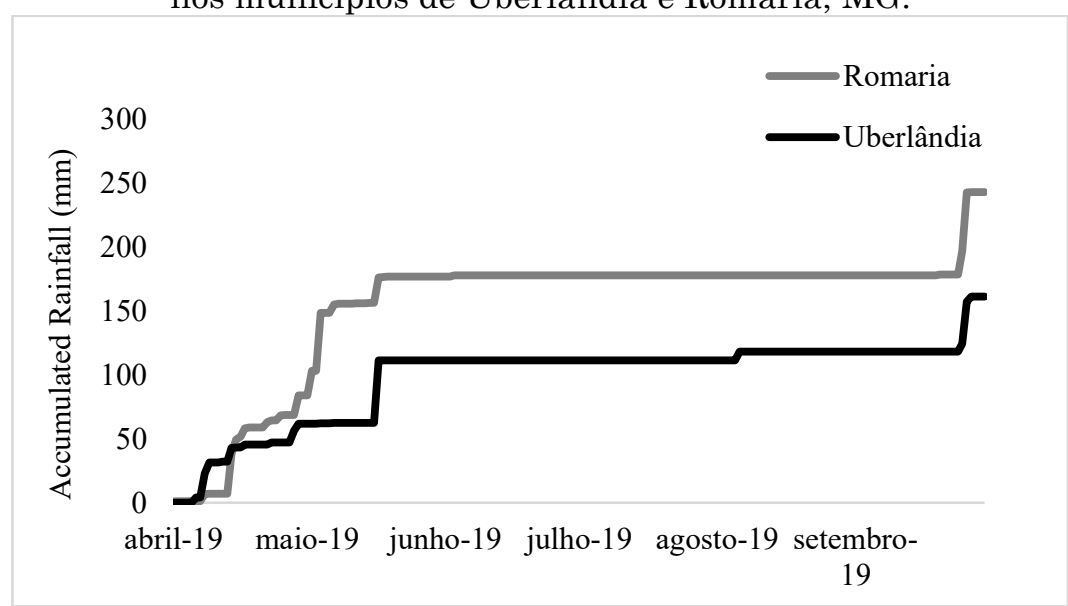

Fonte dos dados: INMET (2020) e Sismet Cooxupé (2020). Elaborado pelOs autores (2021).

Figura 3 - Temperatura $\left({ }^{\circ} \mathrm{C}\right)$ no mês da coleta das amostras de solos nos municípios de Uberlândia e Romaria, MG. Fonte: Instituto Nacional de Meteorologia e Sismet Cooxupé, 2019.

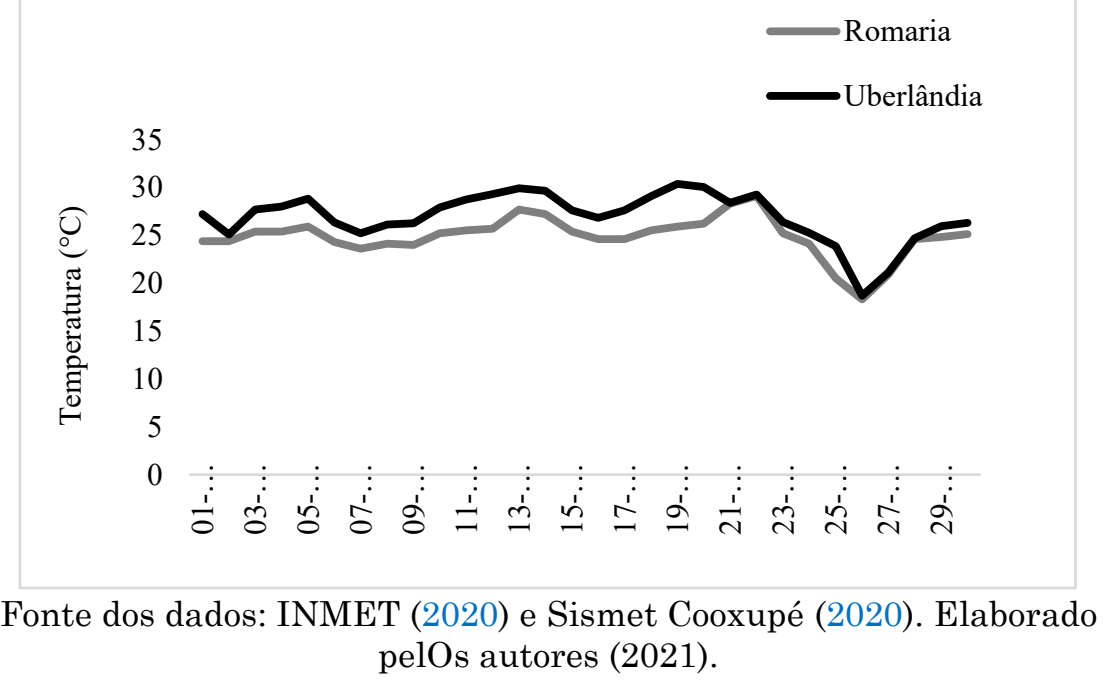

As 10 amostras avaliadas nesse trabalho (Tabela 1) foram peneiradas em malha de $2 \mathrm{~mm}$ e utilizadas para análises químicas, microbianas (unidades formadoras de colônia) e bioquímicas (atividade enzimática, carbono da biomassa e respiração basal). 
Análises químicas, bioquímicas e microbianas do solo

Os parâmetros de fertilidade: pH (em água), fósforo $(\mathrm{P})$ - $\mathrm{P} \mathrm{meh}^{-1}$ - Extrator Mehlich ${ }^{-1}$ potássio (K) em que $\mathrm{K}=\left[\mathrm{HCl} 0,05 \mathrm{~mol} \mathrm{~L}^{-1}+\mathrm{H}_{2} \mathrm{SO}_{4} 0,0125\right.$ $\mathrm{L}^{-1}$, cálcio $(\mathrm{Ca})$, magnésio $(\mathrm{Mg})$, matéria orgânica (M.O.) - Método Colorimétrico, capacidade de troca de cátions efetiva (CTC) e saturação por bases (V \%) foram analisados de acordo com Teixeira (2017).

$\mathrm{O}$ número de unidades formadoras de colônia (UFC) foi determinado em triplicata em meios de cultura seletivos para bactérias e actinobactérias. Utilizou-se o método de diluição seriada e espalhamento em placa com meio de cultura sólido. Para o cultivo das actinobactérias utilizou-se meio SCN (TAVARES, 2019) suplementado com antifúngico nistatina e o antibiótico estreptomicina. Para o cultivo de bactérias utilizou-se meio Ágar nutriente (CARDOSO, 2012) suplementado com nistatina. As placas foram mantidas em temperatura de $25 \pm 2^{\circ} \mathrm{C}$, sob fotoperíodo de 12 horas, durante três dias para actinobactérias e bactérias. Os resultados foram expressos em número de unidades formadoras de colônias por $1 \mathrm{~g}$ grama de solo.

Os solos destinados à avaliação do carbono da biomassa microbiana e respiração basal tiveram a sua umidade ajustada a $60 \%$ da capacidade de retenção de água pelo método gravimétrico de acordo com a metodologia de Silva et al. (2007). Para a análise de carbono da biomassa microbiano (CBM) foi utilizado o método de fumigação-extração (FE), que seguiu a metodologia descrita por Souza et al. (2015). A quantificação do carbono nos extratos oriundos da amostra de solo foi realizada de acordo com a metodologia de Mendonça e Da Matos (2005). Já a avaliação da respiração basal (RBS) foi realizada segundo o procedimento de Silva et al. (2007).

A atividade da B-glicosidase (GLI) foi determinada de acordo com a metodologia de Eivazi e Tabatai (1988), a determinação da fosfatase (FOSF) foi realizada de acordo com
Tabatabai e Bremner (1969) com modificações e a determinação da enzima arilsulfatase (ARIL) foi realizada segundo Tabatabai e Bremner (1970). Os resultados dessa análise foram expressos em $\mu \mathrm{g}$ produto liberado g solo $\mathrm{seco}^{-1}$ $\mathrm{h}^{-1}$.

Os dados de fertilidade do solo, CBM, RBS, atividade das enzimas e população de bactérias e actinobactérias foram submetidos à análise de variância (ANOVA) e as comparações entre médias foram realizadas pelo teste de SkottKnott a $5 \%$ de significância com auxílio do programa SISVAR 5.7 (FERREIRA, 2019). Em adição, foi realizada a Análise de Componentes Principais (PCA), que é uma técnica de ordenação linear, utilizando o software CANOCO versão 4.5 (ter BRAAK; SMILAUER, 2002).

Para a interpretação dos resultados dos bioindicadores deste trabalho utilizou-se o modelo Fertbio elaborado por Mendes et al. (2018), pois esse método incorpora indicadores microbianos e de fertilidade nas análises do solo no Brasil. Por este modelo é possível interpretar indicadores B-Glicosidade e Arilsulfatase para Latossolos Vermelhos argilosos de C Cerrado, sob cultivos anuais para amostras de solo secas ao ar. Apesar de nem todas as propriedades possuírem esse tipo de solo, esse modelo de interpretação foi utilizado para todas as propriedades desse estudo. Os indicadores foram comparados pela razão de seus valores para cada sistema. Quanto maior for o resultado, maior é a sensibilidade do bioindicador para as mudanças nos sistemas de manejo (MENDES et al., 2018).

\section{RESULTADOS E DISCUSSÃO}

De acordo com a análise dos atributos químicos do solo (Tabela 2), as variáveis $\mathrm{pH}, \mathrm{Ca}, \mathrm{Mg}$, M.O., CTC efetiva e V\% encontram-se em maior proporção nos sistemas de manejo agroecológico do que nas áreas de pasto. 
Tabela 2 - Atributos químicos nas amostras de solo coletadas nas áreas de cultivo agroecológico (CA) e de pasto.

\begin{tabular}{|c|c|c|}
\hline Variáveis Químicas & $\mathrm{CA}$ & Pasto \\
\hline $\mathrm{pH} \mathrm{H}_{2} \mathrm{O}$ & $6,99 *$ & $5,84^{*}$ \\
\hline P meh-1 (mg dm $\left.{ }^{-3}\right)$ & 99,49 & 10,52 \\
\hline $\mathrm{K}\left(\mathrm{mg} \mathrm{dm} \mathrm{m}^{-3}\right)$ & 726,60 & 70,58 \\
\hline $\mathrm{Ca}\left(\mathrm{cmolc} \mathrm{dm}^{-3}\right)$ & $6,14^{*}$ & $1,62^{*}$ \\
\hline $\mathrm{Mg}\left(\mathrm{cmolc} \mathrm{dm}^{-3}\right)$ & $3^{*}$ & $0,64^{*}$ \\
\hline M.O. (dag Kg-1) & 3,09 & 1,53 \\
\hline CTC efetiva & $11,02^{*}$ & $2,47^{*}$ \\
\hline $\mathrm{V} \%$ & $87,59^{*}$ & $54,03^{*}$ \\
\hline
\end{tabular}

Fonte: Os autores (2021). Números seguidos com asterisco $\left(^{*}\right)$ representam diferença significativa entre os dois tratamentos pelo teste de Scott-Knott à 5\% de significância.

As maiores proporções dos atributos $\mathrm{pH}, \mathrm{Ca}$, Mg, M.O., CTC efetiva e V\% nas áreas de CA se devem possivelmente à incorporação de matéria orgânica e pela diversidade de espécies nessas áreas de cultivo. Provavelmente a M.O. não se mostrou significativa por ter sido retirada a serrapilheira antes da coleta da amostra. É importante salientar que os atributos químicos podem ter tido alteração devido a adição de insumos agrícolas nas propriedades 1 e 3 .

Resultados semelhantes foram relatados por Santiago et al. (2018), de acordo com esse trabalho foi observado que o $\mathrm{pH}$ na camada de 0 a $20 \mathrm{~cm}$ de solos em transição para sistemas de cultivo agroecológicos apresentaram correlações positivas ao longo do tempo de uso, comprovando-se que nesses solos em transição os valores de $\mathrm{pH}$ tendem a aumentar. O presente trabalho também obteve resultados congruentes com o estudo Obeng e Aguilar (2015), em que os solos das agroflorestas de cacau apresentaram uma maior concentração de $\mathrm{Ca}$ e $\mathrm{Mg}$ que em relação as áreas de florestas nativas da região.

$\mathrm{Na}$ pesquisa realizada por Samani et al. (2020), obtiveram-se maiores proporções de $\mathrm{Mg}$ no solo de sistemas agroflorestais do que nas amostras de solo de outros sistemas de cultivo. Segundo os autores, isso pode ter ocorrido devido às copas das árvores que criaram condições adequadas para intemperismo mineral com temperatura e umidade ideais e, assim, maiores quantidades de $\mathrm{Mg}$ são liberadas. Este motivo explica as menores concentrações de $\mathrm{Mg}$ nas áreas de pasto.
De acordo com Kassa (2018), valores de pH e CTC mais eleavados em sistemas agroflorestais em relação às áreas de monocultura está, provavelmente, relacionada a altos teores de matéria orgânica, ligados à queda de folhas das árvores e à proteção contra a erosão do solo fornecida pelas mesmas. Segundo o autor, a maior CTC do solo está relacionada com os altos teores de argila e com a matéria orgânica. Isso está condizente com esse trabalho, pois as áreas de CA obtiveram uma maior CTC do que as áreas de pasto, provavelmente devido à maior quantidade de resíduos vegetais presentes nas áreas de CA. De acordo com Teixeira (2013), o V\% é indicativo das condições gerais de fertilidade do solo, uma vez que o V\% é reflexo da soma de bases e da CTC efetiva. Desse modo, é possível notar que as áreas sob manejo agroecológico possuem uma maior fertilidade em relação às áreas de pasto.

Em relação às análises enzimáticas foi constatado que a concentração da enzima Bglicosidase foi significativamente superior nas amostras cultivo agroecológico em relação às amostras de solo de pasto (Figura 4). A maior concentração dessa enzima nas áreas de CA se deve possivelmente à maior quantidade de resíduos vegetais no solo que são provenientes da grande diversidade de vegetação perene desse cultivo e também pelas práticas de reciclagem de biomassa utilizada pelos produtores rurais. 
Figura 4 - Concentração de enzimas B-glicosidase, Fosfatase e Arilsulfatase nos manejos de Cultivo Agroecológico e de Pasto. Os Valores das atividades enzimáticas foram expressos em $\mu$ g produto liberado g solo seco $^{-1} \mathrm{~h}^{-1}$.

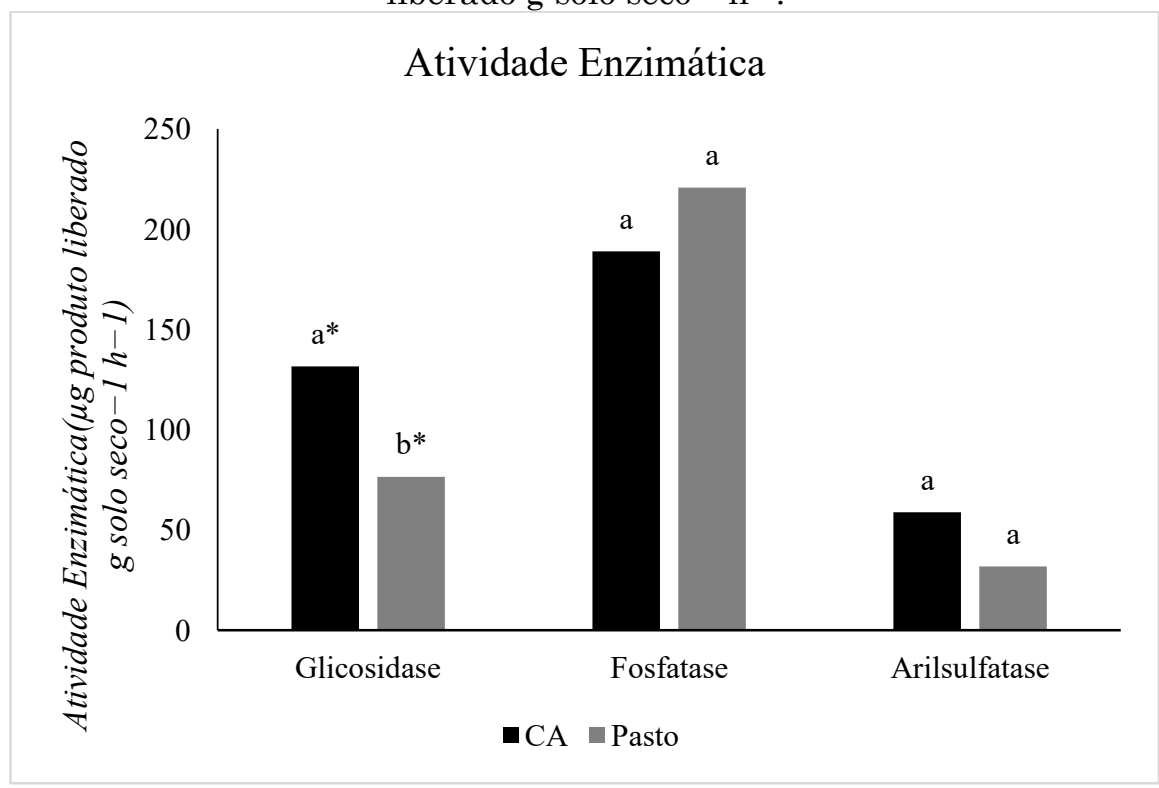

Fonte: Os autores (2021).

Segundo Paudel et al. (2011), a maior atividade de certas enzimas do solo é aprimorada por práticas de conservação, como o cultivo agroecológico, que podem elevar outros parâmetros de qualidade do solo, como conteúdo de matéria orgânica, agregação e infiltração de água no solo, sustentabilidade e produtividade do mesmo.

No estudo realizado por Vallejo et al. (2010) foi analisada a atividade enzimática da BGlicosidase e observou-se uma maior concentração dessas enzimas no sistema agroflorestais de 12 anos idade em relação à área de pastagem convencional. Segundo Paudel et al. (2011), a maior atividade da enzima Bglucosidase em tratamentos de vegetação perene pode ser explicada pelo acúmulo de biomassa da vegetação perene no solo.

Em relação à análise de microrganismos, houve um aumento significativo na quantidade de actinobactérias das amostras de CA em relação às respectivas áreas de pasto (Figura 5). Em adição, as colônias de actinobactérias encontradas no pasto apresentaram-se muitos pequenas e de cor branca, enquanto aquelas encontradas nas áreas CA apresentaram-se com tonalidade amarela. Os dados populacionais de actinobactérias estão de acordo com o estudo de Beule et al. (2020), em que esses microrganismos demonstraram, de forma geral, estarem em maior abundância nas amostras de solo de CA do que nos solos de monoculturas. Isso ocorreu devido ao aumento da biomassa vegetal e da diversidade acima do solo, o que aumentou a entrada de serapilheira e o aumento da quantidade e diversidade de exsudatos radiculares. 
Figura 5 - Indicadores biológicos de qualidade do solo (RBS, CBM, actinobactérias e bactérias) nas amostras de solo coletadas nas propriedades de cultivo agroecológico (CA) e pasto.

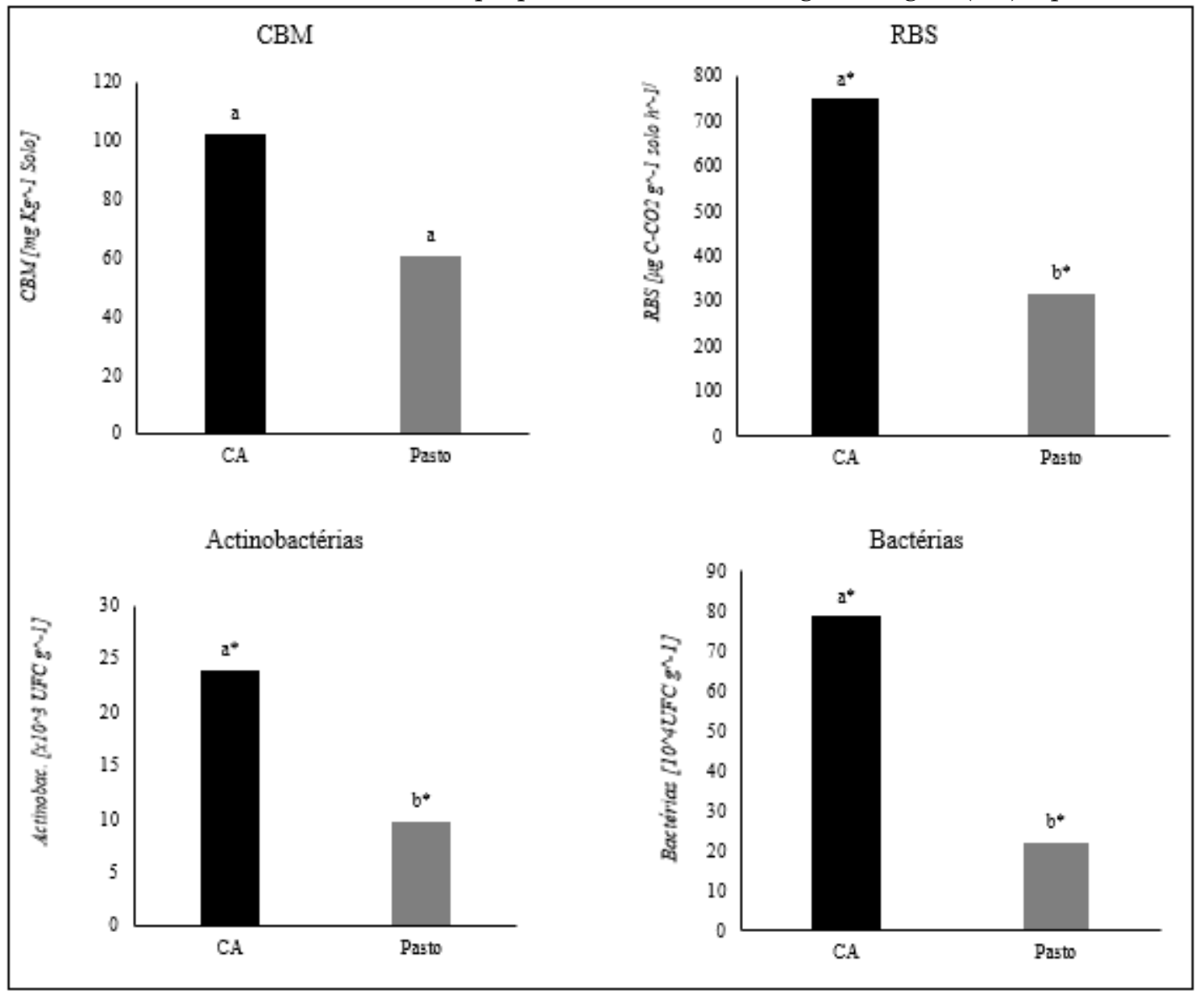

Fonte: Os autores (2021). Médias seguidas por letras similares não diferem significativamente pelo teste Scott-Knott a 5\% de significância.

Para os valores de RBS observou-se que as áreas de cultivo agroecológico apresentaram valores significativamente superiores às áreas de pastagens tidas como referência para cada propriedade (Figura 5). Esse resultado representa uma maior atividade dos microrganismos nas áreas $\mathrm{CA}$, o que pode ter ocorrido por conta da maior quantidade de unidades formadoras de colônias de bactérias e actinobactérias nesse solo, além da maior quantidade de resíduos orgânicos depositados.

No estudo realizado por Tian et al. (2013), constataram que a respiração basal foi significativamente maior para os sistemas agroflorestais do que para o sistema de monocultura. Uma taxa mais alta de respiração basal nas agroflorestas pode ser devida à existência de uma grande disponibilidade de substratos de carbono lábeis.

No presente trabalho constatou-se que as bactérias se apresentaram em quantidade superior nas áreas de CA do que nas respectivas áreas de pasto. As amostras com unidades formadoras de colônias de bactérias, provenientes das áreas de pasto, possuíam coloração branca. Já as colônias de bactérias encontradas nas áreas CA eram predominantes de coloração amarelo/laranja.

Os resultados aqui apresentados estão de acordo com o estudo de Henneron et al. (2015), e afirmaram que a quantidade de bactérias presentes no solo de sistema orgânico é significativamente maior que nos solos de manejo convencional. Além disso, a abundância de certos genes bacterianos foi positivamente correlacionada com o $\mathrm{C}$ orgânico do solo, o $\mathrm{N}$ total, o $\mathrm{P}$ disponível na planta e o $\mathrm{K}$ e $\mathrm{Mg}$ trocáveis (BEULE et al., 2019).

$\mathrm{O}$ biplot resultante da análise de componentes principais (PCA), com base nos indicadores de qualidade do solo e subáreas de amostragem, expressa claramente a relação existente entre algumas atividades enzimáticas e os dois tipos de manejo: cultivo agroecológico (CA) e pasto. De acordo com a análise, o eixo 1 explicou $60,8 \%$ a relação bioindicadoresambiente e, juntamente com o eixo 2, explicou $16,5 \%$ da variação dos dados (Figura 6 ). 
Figura 6 - Biplot das diferentes áreas de manejo e dos indicadores de qualidade do solo - ACT: actinobactérias, ARIL: Arilsulfatase; BAC: Bactérias; Ca: Cálcio; CBM: Carbono da Biomassa Microbiana; FOSF: Fosfatase, GLI: B-glicosidase; K: Potássio; Mg: Magnésio; M.O.: Matéria Orgânica; P: Fósforo; RBS: Respiração Basal do Solo; V\%: Saturação por Bases na CTC potencial

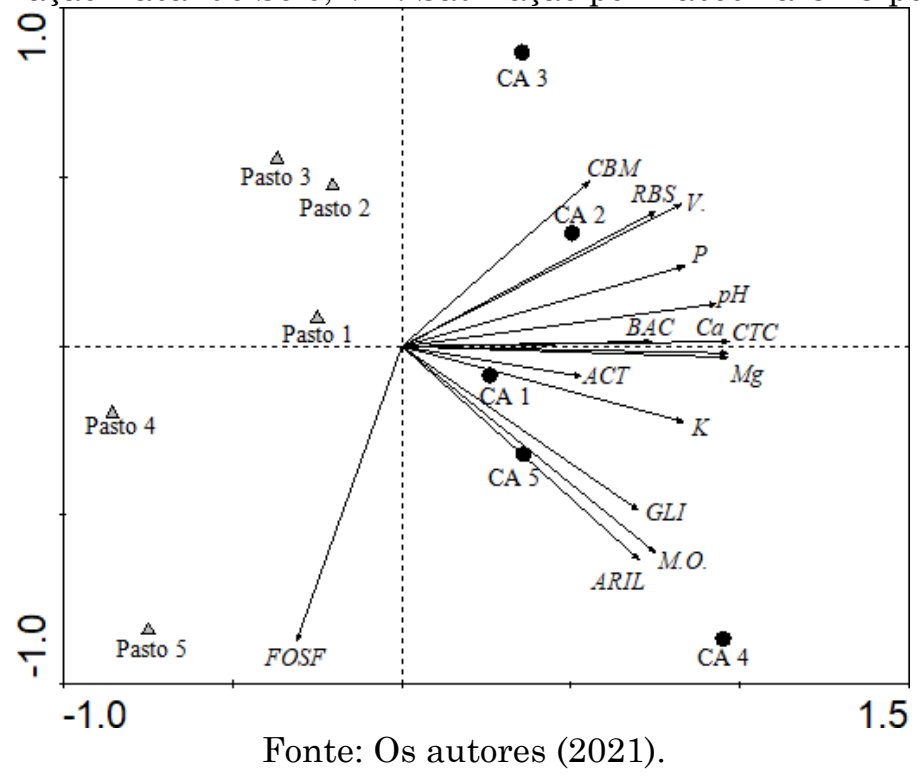

Foi possível observar que as áreas de CA estão mais relacionadas com os maiores valores das variáveis de qualidade do solo, com exceção da FOSF, o que é um indicativo que essas áreas possuem qualidade superior. Em contrapartida, as áreas de pasto estão inversamente relacionas com os indicadores de qualidade do solo. $\mathrm{O}$ eixo 1 é o que mais separa os tipos de manejo. Assim, as variáveis que mais diferenciam os $\mathrm{CAs}$ das pastagens são o $\mathrm{Mg}, \mathrm{Ca}$, bactérias, $\mathrm{pH}$, CTC e actinobactérias. Possivelmente, a maior relação das variáveis de qualidade do solo com o CA se deve por esse manejo aumentar a quantidade de resíduos vegetais de diversas espécies agrícolas e por aumentar a cobertura vegetal, evitando a lixiviação dos nutrientes.

As amostras de solo do CA4 e CA5 apresentaram uma maior relação com a concentração de M.O. e com as atividades de arilsulfatase e B-glicosidase. A atividade enzimática dessas enzimas está positivamente relacionada com a concentração de M.O. no solo (WALMSLEY; SKLENIČKA, 2017; PAUDEL et al. 2011). A maior relação dessas amostras com a matéria orgânica, pode ser explicada pelas práticas que promovem a reciclagem de nutrientes realizadas pelo produtor rural da propriedade 3 .

Os solos avaliados neste trabalho possuem tipologias diferentes de Latossolos Vermelhos (Tabela 1). Mesmo havendo essa distinção entre a classificação dos solos, comparando os valores obtidos de B-Glicosidade e de Arilsulfatase com os dados da tabela de interpretação de bioindicadores de Mendes et al. (2018) (Tabela 3) foi possível demonstrar que as amostras coletas nas áreas de SAF e cultivo agroecológico apresentaram uma melhor classe de interpretação do que as amostras de solo de pasto (Tabela 4).

Tabela 3. Interpretação de bioindicadores para a atividade das enzimas de B-Glicosidade e de Arilsulfatase nas amostras de solo coletadas nas propriedades com sistemas agroflorestais (SAF) de cultivo agroecológico (CA).

\begin{tabular}{ccc}
\hline Amostras & B-Glicosidade & Arilsulfatase \\
\hline CA & Adequado & Moderado \\
Pasto & Moderado & Moderado
\end{tabular}

Fonte: Os autores (2021). Segundo Mendes et al. (2018), a atividade da B-Glicosidade $\leq 66$ é considerada baixa; entre 67-115 é considerada moderada; e >116 considerada adequada. Para a enzima arilsulfatase valores $\leq 30$ são considerados baixos; entre 31-70 considerados moderados; e $>71$ adequados. 
De acordo com Mendes et al. (2018), é possível interpretar indicadores B-Glicosidade e Arilsulfatase para Latossolos Vermelhos argilosos de cerrado, sob cultivos anuais para amostras de solo secas ao ar. Segundo o autor, um valor baixo dos indicadores pode demonstrar que práticas de manejo inadequadas estejam sendo utilizadas na área. Já os maiores valores destes bioindicadores podem ser entendidos como valores desejáveis que devem ser mantidos para o bom funcionamento do solo. De acordo com o bioindicador B-Glicosidade a qualidade do solo nas áreas cultivo agroecológico são melhores do que nas áreas de pasto, já para Arilsulfatase não houve diferença.

$\mathrm{Na}$ tabela 4 estão apresentadas as comparações dos diversos indicadores de qualidade do solo entre as diferentes áreas de estudo (cultivo agroecológico e pasto).

Tabela 4. Razão entre as variáveis de solo coletadas nas áreas de cultivo agroecológico (CA), e nas áreas de pasto das áreas subjacentes.

\begin{tabular}{|c|c|c|c|c|c|c|}
\hline $\begin{array}{c}\text { Tratamentos / } \\
\text { Amostras }\end{array}$ & $\begin{array}{r}\text { CA1 / } \\
\text { Pasto } 1\end{array}$ & $\begin{array}{c}\text { CA2 / } \\
\text { Pasto2 }\end{array}$ & $\begin{array}{l}\text { CA3 / } \\
\text { Pasto3 }\end{array}$ & $\begin{array}{c}\text { CA4 / } \\
\text { Pasto4 }\end{array}$ & $\begin{array}{c}\text { CA5 / } \\
\text { Pasto } 5\end{array}$ & $\begin{array}{l}\text { Média CA } \\
\text { / Média } \\
\text { Pasto }\end{array}$ \\
\hline CBM & 3,00 & 1,22 & 4,75 & 1,33 & 1,13 & 1,68 \\
\hline RBS & 1,75 & 1,34 & 12,27 & 2,82 & 3,17 & 2,35 \\
\hline B-Glicosidade & 2,22 & 2,03 & 1,35 & 2,58 & 0,86 & 1,69 \\
\hline Arilsulfatase & 1,89 & 1,42 & 1,56 & 3,96 & 1,09 & 1,85 \\
\hline Fosfatase ácida & 0,98 & 0,85 & 0,45 & 1,68 & 0,71 & 0,86 \\
\hline $\begin{array}{c}\text { Colônias de } \\
\text { Actinobactérias }\end{array}$ & 2,04 & 7,55 & 1,00 & 12,38 & 6,58 & 2,44 \\
\hline $\begin{array}{c}\text { Colônias de } \\
\text { Bactérias }\end{array}$ & 5,81 & 4,36 & 17,50 & 2,24 & 1,94 & 3,57 \\
\hline $\mathrm{pH}$ & 1,16 & 1,08 & 1,35 & 1,22 & 1,20 & 1,20 \\
\hline M.O. & 1,12 & 1,60 & 1,64 & 5,45 & 1,51 & 2,03 \\
\hline $\mathrm{P}$ & 0,72 & 38,50 & 14,62 & 10,25 & 16,10 & 9,46 \\
\hline $\mathrm{K}^{+}$ & 0,82 & 2,50 & 4,25 & 17,36 & 44,95 & 10,30 \\
\hline $\mathrm{Ca}^{2+}$ & 1,58 & 1,79 & 5,90 & 6,20 & 9,97 & 3,78 \\
\hline $\mathrm{Mg}^{2+}$ & 1,40 & 2,73 & 6,67 & 7,98 & 113,50 & 4,67 \\
\hline CTC & 1,50 & 2,12 & 5,58 & 7,85 & 15,51 & 4,46 \\
\hline $\mathrm{V} \%$ & 1,19 & 1,25 & 2,28 & 1,34 & 3,78 & 1,62 \\
\hline
\end{tabular}

Fonte: Os autores (2021).

Todas as variáveis, com exceção da atividade da enzima fosfatase ácida, foram maiores nas áreas de CA em relação à área de pasto, já que foram obtidos valores maiores que 1 . As variáveis que obtiveram diferenças mais acentuadas foram o $\mathrm{K}, \mathrm{P}, \mathrm{Mg}^{2+}, \mathrm{Ca}^{2+}$, CTC e colônias de bactérias demonstrando que estas variáveis são mais sensíveis às mudanças de acordo com o sistema de manejo. As variáveis $\mathrm{K}$, $\mathrm{P}, \mathrm{Mg}^{2+}, \mathrm{Ca}^{2+}$, CTC dos CA possivelmente deram valores mais elevados devido ao acréscimo de insumos externos, os quais são permitidos pelo órgão que realiza a certificação dos produtos orgânicos, durante o manejo. Os indicadores RBS, colônias de actinobactérias, CBM, Arilsulfatase, $\mathrm{pH}, \mathrm{MO}$ e V\% também se destacaram e se mostraram sensíveis à mudança de manejo.
Assim, as variáveis colônias de bactérias, colônias de actinobactérias, B-Glicosidade e, $\mathrm{pH}$ se mostram como possíveis indicadores de qualidade do solo, por terem se mostrado sensíveis (Tabela 4). Além disso esses indicadores citados acima mostraram diferença significativa entre as amostras de CA e Pasto no teste de média (Tabela 2, Figura 4 e Figura 5) e também pela maior relação desses indicadores com as áreas de CA, como mostrado na PCA (Figura 6)

\section{CONSIDERAÇÕES FINAIS}

As seguintes variáveis de qualidade do solo demostraram ser sensíveis à diferença de 
manejo entre o cultivo agroecológica e às áreas de pasto: respiração basal, B-glucosidase, colônias de bactérias e de actinobactérias e $\mathrm{pH}$, sendo possível utilizar essas variáveis como indicadores de qualidade do solo. Outras variáveis como $\mathrm{K}, \mathrm{P}, \mathrm{Mg}^{2+}, \mathrm{Ca}^{2+}$, CTC, não foram consideradas como bons indicadores nesse trabalho por, possivelmente, terem sofrido alteração em seus valores devido ao acréscimo de insumos externos pelos agricultores, insumos que são permitidos pelo órgão que realiza a certificação dos produtos orgânicos durante o manejo.

Os indicadores respiração basal, Bglucosidase, $\mathrm{pH}$, colônias de bactérias e de actinobactérias apresentaram ser capazes de identificar alterações do funcionamento do solo nas áreas de agricultura familiar. A maior qualidade do solo das áreas de cultivo agroecológico resultou em maiores valores dessas variáveis. Possivelmente esses manejos apresentam maiores atividades das suas funções básicas, como movimentação e fornecimento de água ao solo e às plantas, ciclagem de nutrientes, resistência a poluentes orgânicos e inorgânicos e alta produtividade.

\section{AGRADECIMENTOS}

Os autores agradecem ao Conselho Nacional de Desenvolvimento Científico e Tecnológico $(\mathrm{CNPq})$ e à Coordenação de Aperfeiçoamento de Pessoal de Nível Superior (CAPES).

\section{REFERÊNCIAS}

ABREU, L. S. et al. Relações entre agricultura orgânica e agroecologia: desafios atuais em torno dos princípios da agroecologia. Desenvolvimento e Meio Ambiente, v. 26, p. 143-160, jul./dez 2012. http://dx.doi.org/10.5380/dma.v26i0.26865

ALTIERI, M.A.; KOOHAFKAN, P. Enduring Farms: climate change, Smallholders and Traditional Farming Communities. Penang: Third World Network, 2008.

ARAÚJO, E. A. et al. Qualidade do solo: conceitos, indicadores e avaliação. Applied Research \& Agrotechnology, Guarapuava, v. 5, n. 1, p. 187-206, jan.-abr. 2012. https://doi.org/10.5777/PAeT.V5.N1.12.

BEULE, L. et al. Conversion of monoculture cropland and open grassland to agroforestry alters the abundance of soil bacteria, fungi and soil-N-cycling genes. PloS one, San Francisco, v. 14, n. 6, p. e0218779, jun. 2019. https://doi.org/10.1371/journal.pone.0218779.

BEULE, L. et al. Poplar rows in temperate agroforestry croplands promote bacteria, fungi, and denitrification genes in soils. Frontiers in Microbiology, Lausanne, v. $10, \quad$ p. 3108, jan. 2020. https://doi.org/10.3389/fmicb.2019.03108.

BÜNEMANN, E. K. et al. Soil quality-A critical review. Soil Biology and Biochemistry, [s.l.], v. 120, p. 105-125, fev. 2018. DOI: https://doi.org/10.1016/j.soilbio.2018.01.030

CARDOSO, E. B.; LUQUINE, L. S.; SILVA, H. S. A. Aplicação conjunta de rizobactérias e bactérias endofíticas para o biocontrole do Fusarium oxysporum f. sp. Cubense. In: Embrapa Mandioca e Fruticultura-Resumo em anais de congresso (ALICE). In: JORNADA CIENTÍFICA EMBRAPA MANDIOCA E FRUTICULTURA, 6., 2012, Cruz das Almas. Anais... Cruz das Almas: Embrapa Mandioca e Fruticultura, 2012., 2012.

CAVALCANTE, W. F. et al. Enzymatic activity of caatinga biome with and without anthropic action. Revista Caatinga, Mossoró, v. 33, n. 1, p. 142-150, 2020. https://doi.org/10.1590/1983-

21252020v33n116rc.

CIACCIA, C. et al. Agroecological Practices and Agrobiodiversity: A Case Study on Organic Orange in Southern Italy. Agronomy, [s.l.], v. 9, n. 2, p. 85, fev. 2019. https://doi.org/10.3390/agronomy9020085.

EIVAZI, F.; TABATABAI, M. A. Glucosidases and galactosidases in soils. Soil Biology and Biochemistry, Elmsford, v. 20, n. 5, p. 601606, dez.1988. https://doi.org/10.1016/00380717(88)90141-1.

FERREIRA, E. P. B.; STONE, L. F.; MARTINDIDONET, C. C. G. População e atividade microbiana do solo em sistema agroecológico de produção. Revista Ciência Agronômica, Fortaleza, v. 48, n. 1, p. 22-31, jan.-mar. 2017. https://doi.org/10.5935/1806-6690.20170003.

FERREIRA, D. F. Sisvar: a Computer Analysis System To Fixed Effects Split Plot Type Designs. Revista Brasileira De Biometria, v. 37, n. 4, p. 529-535, dez. 2019. https://doi.org/10.28951/rbb.v37i4.450

HENNERON, L. et al. Fourteen years of evidence for positive effects of conservation agriculture and organic farming on soil life. Agronomy for Sustainable Development, [s.l.], v. 35, n. 1, p. 169-181, abr. 2015. https://doi.org/10.1007/s13593-014-0215-8.

INMET - INSTITUTO NACIONAL DE METEOROLOGIA. Banco de dados meteorológicos para ensino e pesquisa. BDMEP, 2020. Disponível em: 
https:/tempo.inmet.gov.br/TabelaEstacoes/A5 07. Acesso em: 10 out. 2020.

KASSA, H. et al. Agro-ecological implications of forest and agroforestry systems conversion to cereal-based farming systems in the White Nile Basin, Ethiopia. Agroecology and Sustainable Food Systems, Philadelphia, v. 42 , n. 2, p. 149-168, nov. 2018. https://doi.org/10.1080/21683565.2017.138242 5.

LAMINE, C.; DAWSON, J. The agroecology of food systems: Reconnecting agriculture, food, and the environment. Agroecology and Sustainable Food Systems, v. 42, n. 6, p. 629 636, fev. 2018. https://doi.org/10.1080/21683565.2018.143251 7

LIMA, S.K. et al. Produção e consumo de produtos orgânicos no mundo e no Brasil. Texto para discussão / Instituto de Pesquisa Econômica Aplicada, Brasília, Ipea, fev. 2020. Diponível em: http://repositorio.ipea.gov.br/bitstream/11058/ 9678/1/TD_2538.pdf. Acesso em: 12 fev. 2021.

MENDONÇA, E. S, DA MATOS E. S. Matéria orgânica do solo: métodos de análises.Viçosa: UFV, 2005.

MENDES, I. C. et al. Bioanálise de solo: como acessar e interpretar a saúde do solo. Embrapa Cerrados-Circular Técnica (INFOTECA-E), Planaltina, 2018. Diponível em:

https://ainfo.cnptia.embrapa.br/digital/bitstre am/item/199833/1/CircTec-38-Ieda-

Mendes.pdf. Acesso em: 12 fev. 2021.

NEREUS - Núcleo de Economia Regional e Urbana da Universidade de São Paulo. Shape files do Brasil. Disponível em: http://nereus.webhostusp.sti.usp.br/?dados=br asil. Acesso em: 10 out. 2020.

OBENG, E. A.; AGUILAR, F. X. Marginal effects on biodiversity, carbon sequestration and nutrient cycling of transitions from tropical forests to cacao farming systems. Agroforestry Systems, [s.l.], v. 89, n. $1, \quad$ p. 19-35, set. 2015.: https://doi.org/10.1007/s10457-014-9739-9.

PAUDEL, B. R.; UDAWATTA, R. P.; ANDERSON, S. H. Agroforestry and grass buffer effects on soil quality parameters for grazed pasture and row-crop systems. Applied Soil Ecology, [s.l.], v. 48, n. 2, p. 125-132, jun. 2011 https://doi.org/10.1016/j.apsoil.2011.04.004.

RAIESI, F.; BEHESHTI, A. Soil C turnover, microbial biomass and respiration, and enzymatic activities following rangeland conversion to wheat-alfalfa cropping in a semiarid climate. Environmental Earth
Sciences, Alemanha, v. 72, n. 12, p. 50735088, jun.

2014. https://doi.org/10.1007/s12665-014-3376-5.

SAMANI, K. M. et al. Effect of land-use changes on chemical and physical properties of soil in western Iran (Zagros oak forests). Journal of Forestry Research, [s.1.], v. 31, n. 2, p. 637 647, out. 2020. https://doi.org/10.1007/s11676018-0799-y.

SANTIAGO, F. S.; MONTENEGRO, S. M. G. L.; PINHEIRO, M. R. A P. Índice de qualidade do solo em cultivo agroecológico e convencional no semiárido potiguar, Brasil. Revista Verde de Agroecologia e Desenvolvimento Sustentável, v. 13, n. 1, p. 97-105, jan.-mar. 2018.

http://dx.doi.org/10.18378/rvads.v13i1.5333

SARMIENTO, E.; FANDINO, S.; GOMEZ, L. Indexes of soil quality. A systematic review. ECOSISTEMAS, Móstoles, v. 27, n. 3, p. 130-139, set. 2018. https://doi.org/10.7818/ECOS.1598.

SILVA, E. E.; AZEVEDO, P. H. S.; DE-POLLY, H. Determinação da respiração basal (RBS) e quociente metabólico do solo (qCO2). Embrapa AgrobiologiaComunicado Técnico (INFOTECA-E), Seropédica, 2007. Diponível em: https://www.infoteca.cnptia.embrapa.br/bitstr eam/doc/627577/1/cot099.pdf. Acesso em: 15 de jul. 2019.

SILVA, R. P. Análise integrada em sistemas agroflorestais de agricultores do assentamento Celso Lúcio, 2019. $84 \mathrm{f}$. Monografia (Graduação em Engenharia Ambiental), Instituto de Ciências Agrárias, Universidade Federal de Uberlândia, Uberlândia, 2019.

COOXUPÉ, SISMET. Dados das Estações Meteorológicas.(novembro, 2019). Recuperado de: http://sismet. cooxupe. com. br, v. 9000. Dispoível em: https://sismet.cooxupe.com.br:9000/dados/esta cao/pesquisarDados/?estCooxupe=1\&cdEstaca $\mathrm{o}=12$. Acesso em: 10 out. 2020.

SKRZYPCZYŃSKI, R. et al. Beyond Supporting Access to Land in Socio-Technical Transitions. How Polish Grassroots Initiatives Help Farmers and New Entrants in Transitioning to Sustainable Models of Agriculture. Land, [s.l.], v. 10, n. 2, p. 214, fev. 2021. https://doi.org/10.3390/land10020214.

SOUZA, L. M. et al. Carbono da biomassa microbiana em Latossolos determinado por oxidação úmida e combustão a temperatura elevada. Pesquisa Agropecuária Brasileira, Brasília, v. 50, n. 11, p. 1061-1070, nov. 2015. https://doi.org/10.1590/S0100204X2015001100009. 
TABATABAI, M. A.; BREMNER, J. M. Arylsulfatase activity of soils. Soil Science Society of America Proceedings, Madison, v. 34, n. 2, p. 225-229, mar. 1969. DOI: https://doi.org/10.2136/sssaj1970.0361599500 3400020016x.

TABATABAI, M. A.; BREMNER, J. M. Use of $\rho$ nitrophenyl phosphate for assay of soil phosphatase activity. Soil Biology and Biochemistry, Elmsford, v. 1, n. 4 p. 301-307, nov. 1970. https://doi.org/10.1016/00380717(69)90012-1.

TAVARES, D. G. et al. Controle biológico de Meloidogyne incognita por isolados de actinomicetos. In: Colloquium Agrariae. ISSN: 1809-8215. 2019. p. 29-36. https://doi.org/10.5747/ca.2019.v15.n2.a282

TEIXEIRA, P. C. et al. Manual de métodos de análise de solo. Rio de Janeiro: Embrapa, 2017.

TEIXEIRA, V. G. Atribuição de tributos do solo e vegetação em sistema agroecológico. Trabalho de conclusão de curso (Ecologia) - Universidade Estadual Paulista, Instituto de Biociências de Rio Claro. UNESP, Rio Claro - SP, 2013.

ter BRAAK, C. J. F.; SMILAUER, P. CANOCO reference manual and CanoDraw for Windows user's guide: software for canonical community ordination (version 4.5). Ithaca: Microcomputer Power; 2002.

TIAN, Y.; CAO, F.; WANG, G. Soil microbiological properties and enzyme activity in Ginkgo-tea agroforestry compared with monoculture. Agroforestry systems, [s.l.], v. 87, n. 5, p. 1201-1210, ago. 2013. https://doi.org/10.1007/s10457-013-9630-0.

VALLEJO, V. E.; ROLDAN, F.; DICK, R. P. Soil enzymatic activities and microbial biomass in an integrated agroforestry chronosequence compared to monoculture and a native forest of Colombia. Biology and Fertility of Soils, Florença, v. 46, n. 6, p. 577-587, maio 2010. https://doi.org/10.1007/s00374-010-0466-8.

WACH, E. Market Dependency as Prohibitive of Agroecology and Food Sovereignty-A Case
Study of the Agrarian Transition in the Scottish Highlands. Sustainability, Basel, v. 13, n. 4, p. 1927, fev. 2021. DOI: https://doi.org/10.3390/su13041927.

WALMSLEY, A.; SKLENIČKA, P. Various effects of land tenure on soil biochemical parameters under organic and conventional farming- Implications for soil quality restoration. Ecological Engineering, [s.l.], v. 107, p. 137-143, out. 2017. https://doi.org/10.1016/j.ecoleng.2017.07.006.

WARMLING, D. et al. Sentidos sobre agroecologia: a produção, distribuição e consumo de alimentos agroecológicos no município de Florianópolis/SC, 2014. 125 f. Dissertação (Pós-graduação em Saúde Coletiva), Centro de Ciências da Saúde, Universidade Federal de Santa Catarina, Florianópolis, 2014.

WOOD, S. A. et al. Functional traits in agriculture: agrobiodiversity and ecosystem services. Trends in ecology \& evolution, Cambridge, v. 30, n. 9, p. 531-539, set. 2015. https://doi.org/10.1016/j.tree.2015.06.013.

\section{CONTRIBUIÇÃO DOS AUTORES}

Ana Flávia Brandão Rocha concebeu o estudo, coletou, analisou os dados, redigiu o texto, realizou trabalho de campo e os experimentos em laboratório. Ana Carolina Silva Siquieroli supervisionou o estudo, coletou os dados, redigiu e revisou o texto realizou trabalho de campo e os experimentos em laboratório. Adriane de Andrade Silva fez trabalho de campo, coletou os dados e revisou o trabalho. Amanda Mendes De Lima Carneiro coletou os dados e fez experimentos no laboratório. Bruno Nery Fernandes Vasconcelos realizou trabalho de campo, coletou os dados e revisou o texto. Danielle Davi Rodrigues Gondim coletou os dados e fez experimentos no laboratório. 